\title{
A Política Externa do Império no Prata e a Missão Bellegarde ao Paraguai (1848-1852)
}

\author{
The Brazilian Empire Foreign Policy Towards \\ the River Plate Basin and the Bellegarde Mission \\ to Paraguay (1848-1852)
}

DOI: $10.21530 /$ ci.v11n3.2016.277

Pedro Henrique Verano ${ }^{1}$

\section{Resumo}

A década de 1840 representa um momento de bastante importância para a política externa brasileira, uma vez que uma reorientação para seus negócios com os países da região do Rio da Prata foi posta em prática. A reorganização de forças que ocorria em praticamente todos os países desse espaço geográfico possibilitou diferentes iniciativas, assim como também demandou esforços reativos do Império para salvaguardar seus interesses. A aproximação que vinha sendo ensejada com o Paraguai, desde o início dessa década, teve grande importância nesse contexto, uma vez que compôs peça importante no tabuleiro estratégico da região, com destaque à rivalidade entre o Império e Buenos Aires. A análise da Missão Bellegarde ao Paraguai, sob o prisma das instituições políticas do Império, procura dar entendimento à formação de concepções de política externa no país e como elas influenciaram a sua atuação diplomática.

Palavras-chave: Brasil Império; Política Externa Brasileira do Império; Década de 1840.

\begin{abstract}
The 1840 is a decade of major importance for the Brazilian foreign policy, as a pragmatic and more active reorientation of the business towards the River Plate region. The reorganization of forces taking place in its geographical space has enabled several initiatives, as well as demanded reactive efforts from the Empire to safeguard its interests. The approach that had been intended with Paraguay since the beginning of the decade, had great importance in this context, having the rivalry between the Empire and Buenos Aires being in its epicenter. The analysis of the Bellegarde Mission to Paraguay, seen through the prism of the Political Institutions of the Brazilian Empire, intends to broaden the understanding of the shaping knowledge the formation of foreign policy concepts in the country and of how they influence diplomatic action.
\end{abstract}

Keywords: Brazilian Empire; Brazilian Empire’s Foreign Policy; 1840s Decade.

1 Doutorando em Relações Internacionais e Professor no Centro Universitário do Distrito Federal (UDF). Artigo submetido em 24/11/2015 e aprovado em 19/05/2016. 


\section{Introdução}

Entre os anos de 1840 e 1853, foram crescentes as tensões políticas na região platina, notadamente pelas disputas de poder entre o Império e Buenos Aires, sob o governo de Juan Manoel Rosas. O projeto expansionista de reconstruir territorialmente o que fora o Vice-Reino do Prata não somente mexia com os interesses brasileiros como, principalmente, de províncias argentinas, do Uruguai e do Paraguai. Progressivamente, diversas movimentações de forças ocorreram entre as partes envolvidas direta e indiretamente neste cenário.

Ao ter como objetivo central analisar a Missão Bellegarde ao Paraguai, este artigo visa compreender como esse esforço diplomático do Império esteve inserido nessa dinâmica de poder, empiricamente embasado na documentação diplomática trocada pelo representante em Assunção e com a chancelaria no Rio de Janeiro. Paralelamente, também são trabalhados os Anais da Câmara dos Deputados, do Senado e as Consultas da Sessão dos Negócios Estrangeiros do Conselho de Estado, onde são buscados tanto a formação de concepções de inserção internacional quanto a influência e o papel das elites políticas nos negócios estrangeiros do país.

Entende-se que é possível compreender o processo de consolidação da política externa brasileira para o Prata à luz de uma série de elementos ao longo da vigência da Missão Bellegarde. A análise documental cumpre, ao longo do artigo, a função de "dar voz" aos agentes de política externa do período destacado, sobre os quais o olhar do analista se debruça com fins de verificar, por meio do process tracing, como e por que determinada ação foi tomada. Tendo em vista o enfrentamento militar que poria frente a frente o Império e Buenos Aires (1851-1852), as dinâmicas de poder anteriores a esse evento ganham suma importância, ao estar nelas a formação dos blocos de alianças que caminhariam para o teatro de guerra.

Sobre as razões que levam Estados a colocarem nos seus cálculos estratégicos formar ou não uma aliança, parte-se das concepções Realistas desenvolvidas por Hans Morgenthau. No tabuleiro político do Sistema Internacional, em que os Estados têm diferentes níveis de poder, esse instrumento diplomático torna-se elemento central para o desenho da distribuição de capacidades entre os atores envolvidos. Conforme se depreende, na existência de um interesse ou inimigo em comum, as alianças tornam-se ferramentas essenciais para pender favoravelmente para si o balanço de poder (MORGENTHAU, 2003, p. 344-347), o que seria percebido como um dos pontos-chave das negociações de Bellegarde em Assunção. 
Inicia-se o artigo com uma breve contextualização histórica da importância do Prata na política externa do Império, à luz das dinâmicas de poder ali configuradas. Em seguida, foca-se a análise direta da documentação diplomática, sobre a qual se destacam as instruções, visando compreender a visão estratégica que norteou esse empreendimento diplomático do Império com o Paraguai. A quarta e mais extensa parte compõe o corpo central deste texto, em que é observada a ação das instituições políticas brasileiras (Parlamento, Conselho de Estado e Ministério dos Negócios Estrangeiros) acerca do andamento dos trabalhos do diplomata acreditado em Assunção. Por fim, chega-se a etapa final da Missão em si, na qual se tem o resultado das negociações à luz do contexto do quadro da região platina.

\section{Contextualização e Precedentes Históricos}

A bacia do Rio da Prata pode ser entendida como uma das principais zonas de disputas de poder na América do Sul, cuja origem remonta ao processo de colonização luso-espanhol e à projeção de poder decorrente, com objetivos de controlar a navegação fluvial para os fins da exploração de metais preciosos e demarcar posições de fronteira no interior. As disputas militares entre o Império e Buenos Aires pelo controle da Banda Oriental são o exemplo de maior impacto de como o domínio sobre essa zona era tido como estratégico. O fim da Guerra da Cisplatina (1828), no entanto, colocou o Brasil em uma posição de relativo distanciamento das questões dessa sub-região, em virtude de pressões de origem interna. O início do Segundo Reinado, por outro lado, não somente influenciou o cenário endógeno como também afetou sobremaneira a posição do país sobre os negócios platinos.

A iniciativa do envio da Missão Pimenta Bueno ao Paraguai (1843) pode ser entendida como uma metonímia da política externa do Império para o Prata, a qual saía de uma política de neutralidade que perdurara por mais de uma década e ensejava progressivos passos mais incisivos (CERVO; BUENO, 2008, p. 109). Embora não tenha produzido tratados formais, esta missão abriu as portas para uma concertação entre ambos os países, a qual iria ser de grande relevância para o tabuleiro estratégico da região. Em decorrência do progressivo crescimento de poder de Buenos Aires, governada por Juan Manoel Rosas², fez-se necessário para

2 Juan Manoel Rosas, nascido em 1793 em Buenos Aires, tornou-se governador da Província de Buenos Aires em 1838, o que consecutivamente lhe dava o mandato de conduzir a política externa da Confederação Argentina (FLORIA; BELSUNCE, 2004, p. 511-513) 
o Império a busca por múltiplas alternativas para evitar o surgimento de uma ameaça em potencial na região platina, ainda mais em virtude das consequências que as guerras civis na região tinham para o Sul do Brasil.

O reconhecimento formal da independência paraguaia, em 1844, provocou contenciosos diplomáticos relevantes entre os governos de Pedro II e Rosas, em função do entendimento argentino de que o Paraguai era parte da Confederação. A intenção de reconstrução territorial do Vice-Reino do Prata mostrava-se uma ameaça aos interesses brasileiros, em virtude de um eventual ganho de poder argentino, além de colocar em risco o tratado de 1828 que deu fim à Guerra da Cisplatina e apaziguou a disputa entre ambo pela sua posse. Conforme a escalada das tensões cresceu, a conformação das forças entre aliados, cujos interesses eram convergentes, esteve na linha de frente das iniciativas diplomáticas dos países envolvidos, dentre as quais a Missão Bellegarde.

Nesse âmbito, também compuseram as agendas temas como o direito de navegação nos rios da região e fronteiras. As diferentes concepções e embasamentos em acordos coloniais apontam para ambos os assuntos como grandes formadores dos conflitos existentes entre os Estados aqui analisados. Com o objetivo de minar a abertura internacional ensejada por Carlos Lopez no Paraguai, assim como das províncias de Corrientes e Entre Rios, o bloqueio à navegação fluvial foi utilizado pelo governo de Buenos Aires como forma de isolar seus adversários, assim como de forçar sua política de centralização das exportações em seu porto. A oposição a esse movimento de Rosas veio não somente do nível local, como provocou uma intervenção naval da França e da Inglaterra, as quais viam nesse fechamento um impedimento para suas políticas comerciais ${ }^{3}$.

\section{As Instruções da Missão}

Do mesmo modo que sua antecessora, a Missão Pimenta Bueno (1844-1847), a comandada por Pedro de Alcântara Bellegarde tinha como uma de suas motivações o posicionamento da Argentina quanto ao Paraguai. Os eventos subsequentes à chegada do primeiro diplomata brasileiro em Assunção muito preocupavam o governo brasileiro, com amplo destaque para a aliança ofensiva firmada entre

3 As intervenções militares francesas e britânicas no estuário do Prata tiveram início em fins da década de 1830, com o objetivo de pressionar o governo de Buenos Aires a permitir a navegação internacional para o comércio nos rios platinos. Perdurando até 1848, foi notável a resistência argentina, principalmente após a intensificação em 1845 do conflito. 
paraguaios e correntinos, que decorreu de uma malfadada tentativa de anexação do território de Missões, gerando o temor de uma retaliação por parte de Rosas. Consequentemente, a forma como a qual Bellegarde deveria proceder ao longo do seu percurso até Assunção fora bastante influenciada pelos acontecimentos que poderiam ser desencadeados na região a qualquer momento (SOUZA, 1970, v. 3, p 1-13).

Neste dado momento, havia esforços em diversas frentes empreendidos por Buenos Aires no âmbito militar. A intervenção franco-britânica, o apoio dado aos Blancos uruguaios na Grande Guerra (1839-1851), assim como as rivalidades internas da própria Confederação, estão dentre os problemas de maior escala com que este caudilho tinha de lidar. Apesar disso, na percepção que norteava a política externa brasileira da época, o temor de uma ação armada contra o Império era uma constante. Conforme se depreende da documentação desta missão ao Paraguai, o Visconde de Olinda - Ministro dos Negócios Estrangeiros do Império (1848-1849) - temia sobremaneira as intenções das forças militares reunidas por Rosas, em 1848, nas margens do Rio Paraná, que poderiam ter como objetivo intervir em território uruguaio a favor do partido Blanco, assim como retaliar o Paraguai pela invasão das Missões ou mesmo atacar o Império por seu apoio aos Colorados e a Carlos Lopez (SOUZA, 1970, v. 3., p. 6).

A despeito do grande interesse do Império na manutenção da independência paraguaia, mais importante era o Brasil estar apto a defender seu território de qualquer invasão, devendo ser considerada a relevância dos recursos empreendidos por causa dos movimentos iniciais da Praieira (SOUZA, 1970, v. 2, p. 34). Depreende-se dessa parte das instruções dadas a Bellegarde que o Império não se considerava capaz para ingressar em um confronto armado com Buenos Aires, em virtude da escassez de recursos militares brasileiros e da relativa superioridade argentina. Por esta razão, pode ser entendido o motivo pelo qual esteve presente dentro do cálculo diplomático do Império a possibilidade de ser firmada uma aliança com os paraguaios, tendo como premissa o fato de Buenos Aires ser um inimigo em comum, e por meio de um instrumento dessa ordem pender ao seu favor a balança de poder regional.

Apesar de a possibilidade de uma guerra entre o Império e a Confederação ser considerada, ao final de 1848, muito mais provável do que no início desse mesmo ano (Conselho de Estado, sessão de 8 de outubro de 1848), o então Chanceler brasileiro temia que um erro de cálculo na posição brasileira pudesse piorar essa já delicada situação, tornando o sigilo da Missão um dos aspectos 
mais importantes para seu sucesso. Caso descoberto pela Argentina que outro diplomata brasileiro fora enviado para Assunção, além de expor os interesses do Império em continuar sua política de aproximação com o Paraguai, poderia ser um gatilho para uma retaliação militar de Rosas (SOUZA, 1970, v. 3, p. 1-13).

Destaca-se, dentre as instruções do Marquês de Olinda, o temor existente de que uma revolução, com origem na própria população paraguaia, pudesse derrubar o governo Lopez e se posicionar favoravelmente à incorporação à Argentina (SOUZA, 1970, v. 3, p. 6), além da já aventada possibilidade belicosa. Se essa hipótese fosse confirmada antes da chegada de Bellegarde a Assunção, deveria esse retirar-se e voltar ao Brasil; caso ocorresse após chegar ao seu destino final, também deveria regressar, deixando o Paraguai à sua própria sorte, sendo considerada por Olinda como "inútil, e até de graves implicações, uma missão diplomática do Brasil naquele Estado” (SOUZA, 1970, v. 2, p. 35). Contudo, outra possibilidade levantada por Olinda cogitava que a invasão de Rosas ocorresse diretamente sobre território imperial, implicando em Bellegarde apressar sua viagem e conduzir as negociações, associando uma guerra feita contra o Império como uma agressão ao próprio Paraguai, por ser ela decorrente do intuito de Rosas de impedir o prosseguimento da independência desse país em relação à Argentina.

Em uma diferente direção, a Seção dos Negócios Estrangeiros do Conselho de Estado, em 8 de outubro de 1848, deu um parecer acerca da política a ser adotada pelo Império assim que tivessem cessado as intervenções francesa e inglesa no Rio da Prata. Embora nos dois pareceres emitidos ainda nessa sessão (esse número justifica-se em função de divergências por parte do Conselheiro Lopes da Gama) não seja mencionada nenhuma questão referente ao Paraguai, inferem-se questões tangentes ao país decorrentes das citações a Rosas e a seu aliado uruguaio, o General Oribe. Em ambos os casos, recomenda-se adotar uma posição de neutralidade, resultante de uma percepção de fragilidade do exército brasileiro para intervir militarmente na região, assim como a da existência de poucos ganhos a serem obtidos pelo Império caso fosse tomada uma postura beligerante.

A hipótese de atuar militarmente na região do Prata teria como incitador maior a tomada de Montevidéu por Oribe, o que poderia contribuir sobremaneira para a anexação do Uruguai por Rosas e que deveria ser evitada ao máximo para não piorar as condições do Brasil no equilíbrio de poder regional. A solução armada deveria ser evitada, tendo os Conselheiros Bernardo Pereira de Vasconcelos e Honório Hermeto Carneiro Leão sugerido, caso Oribe chegasse a dominar a capital uruguaia, formular um tratado definitivo de paz (em substituição ao provisório 
assinado em 1828) e adiar o reconhecimento do governo do general até que uma assembleia constitucionalmente eleita confirmasse a legitimidade de sua presidência no país. Divergentemente, apesar de levar em consideração o receio do Encarregado dos Negócios Estrangeiros no Uruguai de uma possível invasão desse país ao Império, Lopes da Gama foi mais incisivo quanto à necessidade de o Brasil manter sua postura de neutralidade, devendo assim reconhecer prontamente a legitimidade do governo de Oribe, caso esse viesse a lograr seu objetivo de entrar em Montevidéu (Conselho de Estado, sessão de 8 de outubro de 1848).

Esse parecer e a situação descrita pelos Conselheiros, comparados com as instruções de Bellegarde, caracterizam a postura relutante quanto à neutralidade do Brasil nas questões platinas. Apesar de ser percebido como altamente necessário evitar a reconstrução territorial do Vice-Reino do Prata, ora o posicionamento brasileiro era favorável à constituição de alianças que mitigassem as diferenças relativas de poder (o que poderia fomentar constrangimentos à provável ação militar rosista), ora era recomendado que se mantivesse um maior afastamento e neutralidade quanto às questões das repúblicas do Prata, com o mesmo objetivo de não fomentar um ataque de Rosas. Embora fosse consistente a visão de que o Brasil não estava nas suas melhores condições de confrontar Buenos Aires, o modo como essa situação deveria ser administrada ainda não estava definida.

As percepções no Império de que Rosas tinha o Brasil como maior rival na América do Sul decorria não somente das declarações emitidas por seu representante no Rio de Janeiro, mas também das recorrentes acusações proferidas por ele na imprensa portenha (Câmara dos Deputados, sessão de 21 de agosto de 1845). De acordo com o Marquês de Olinda, possível era que esses atos midiáticos feitos por Rosas tivessem como objetivo fomentar em meio à população buenairense um sentimento contrário ao Brasil, de modo a angariar maior apoio para uma possível guerra. Ao ser seguida essa mesma linha de pensamento, também é importante ser considerada a percepção que Olinda tinha acerca dos feitos e êxitos de Rosas, os quais provocavam a criação de um certo messianismo sobre sua figura em meio à população das mais diversas partes da região platina, ao ser atribuída a ele a imagem de grande libertador que iria tirar os povos do domínio autoritário dos caudilhos.

As ações diplomáticas empreendidas pelo Império para o Prata exemplificam a relutância existente no pensamento político do país acerca da tomada de uma postura mais incisiva quanto aos seus negócios na sub-região. Embora seja constatável que, até 1842 , o Brasil adotava uma neutralidade quanto aos conflitos 
existentes na Argentina e nos seus desdobramentos no Uruguai e Paraguai, não é possível afirmar que esse posicionamento desapareceu repentinamente, dando lugar a uma postura intervencionista. O fortalecimento de Rosas e de seus opositores caracterizava-se como uma das principais razões para o surgimento de uma percepção dentro dos principais quadros do Império da necessidade de alteração na política externa para a região. Ao passo que as revoltas contra o governo do Rio de Janeiro, como a Farroupilha (1845), eram solucionadas, maiores recursos estratégicos eram disponibilizados ao governo brasileiro para que pudesse, efetivamente, defender seus interesses. Na esfera econômica, as Tarifas Alves Branco (1844) abriram espaço para a discussão de outros temas nas instituiçõos, pela grande atenção dada ao Sistema de Tratados Desiguais e suas consequências para o país (CERVO, 1981, p. 49-51; MANCHESTER, 1973)4.

Ao longo da Missão, uma das principais divergências entre os governos brasileiro e paraguaio deveu-se às interpretações destes acerca da necessidade da formação de uma aliança contra Rosas. Ao passo que Carlos Lopez almejava uma que contivesse cláusulas tanto ofensivas quanto defensivas, era desaconselhado ao imperador uma que tivesse como fim atacar Buenos Aires. Subsequentemente, questionavam fortemente a viabilidade de uma aliança mesmo que defensiva, por seus integrantes considerarem que grande parte dos ônus previstos em uma guerra recaíssem sobre os ombros do Brasil. Embora o cálculo estratégico feito pela diplomacia brasileira evitasse ao máximo que seus contatos iniciais com o governo paraguaio predispusessem retaliações de Rosas (Conselho de Estado, Sessão de 15 de maio de 1847), os protestos feitos por seu agente diplomático no Rio de Janeiro demonstram o quanto o reconhecimento da independência paraguaia fomentou sua rivalidade com o Império (Conselho de Estado, sessão de 11 de junho de 1845).

Diferentemente das instruções dadas a Pimenta Bueno, as de Bellegarde tinham ênfase nos crescentes conflitos existentes na região do Prata, decorrentes da postura crescentemente intervencionista de Rosas no Uruguai e na navegação fluvial. As ações paraguaias, tanto as diplomáticas quanto as militares, também contribuíram em grande parte para que houvesse um grande destaque à segurança regional,

4 É denominado como Sistema de Tratados Desiguais a série de acordos comerciais firmados entre o Brasil e diversos países europeus, com destaque para o com a Inglaterra (1828), à luz do processo de obtenção do reconhecimento da independência política de Portugal. Conquanto se tenha obtido êxito na esfera política, entende-se que os ônus econômicos decorrentes das baixas tarifas concedidas à importação foram um preço desproporcionalmente alto pago pelo Império, tendo em vista, inclusive, a vitória prévia na guerra de independência. Para mais detalhes ver Cervo, 1981. 
como a formação de alianças, ou mesmo da conformação de forças e estratégias para o caso de um ataque buenairense ao Paraguai. Tendo sido sanadas por seu antecessor questões relativas ao reconhecimento da independência paraguaia e à navegação dos rios internacionais (que caso, formalmente acordada, deveria ser restrita às embarcações dos países tributários dos cursos d'água), restaram a Bellegarde negociações bastante polêmicas. Dentre estas, grande destaque foi dado à formação de possíveis alianças contra a Confederação Argentina, ao passo que as questões lindeiras ficaram para um segundo plano. A razão para essa discrepância pode ser encontrada em dois fatores complementares:

1. A preponderância da tese brasileira de que era necessário formar uma comissão para analisar melhor o uti possidetis de facto $^{5}$ das regiões contestadas;

2. O maior impacto que o poder de Rosas tinha sobre as percepções das prioridades do relacionamento bilateral entre Brasil e Paraguai, tornando-o o grande ponto de convergência entre ambas as diplomacias.

\section{Instituições Políticas do Império e a Missão Bellegarde}

Ao longo da vigência da Missão Bellegarde (1848-1852), percebe-se uma baixa atuação direta das instituições políticas do Império do Brasil nos temas negociados por esse diplomata com o governo paraguaio. Embora praticamente não tenham sido debatidas no âmbito do Parlamento e do Conselho de Estado as relações entre o Brasil e o Paraguai, não é possível afirmar que a influência do pensamento dos homens de Estado que compunham esses órgãos de assessoramento do Imperador foi nula. Se ao longo do mandato de seu antecessor fora produzida grande quantidade de Atas do Conselho de Estado (por meio das quais as consultas feitas pelo Poder Executivo obtinham respostas das personalidades de maior importância e respeito no Império) (VERANO, 2014), entre os anos de 1848 e 1852 há um silêncio desse grupo político, assim como do Parlamento.

5 O princípio do uti possidetis de facto foi consagrado na formação das fronteiras coloniais portuguesas na América do Sul por Alexandre de Gusmão no Tratado de Madrid (1750). Embora não tenha existido um engajamento significativo da política externa brasileira em negociações lindeiras ao longo das duas primeiras décadas de independência, progressivamente foram surgindo na pauta diplomática com seus vizinhos, com a finalidade de evitar disputas militares por terras. Ao fim da década de 1840, as figuras de Duarte da Ponte Ribeiro e de Paulino José Soares de Souza surgem como os principais defensores desse princípio como alicerce nas negociações de fronteira do Brasil (SOARES, 1973; GOES, 1991; CORTESÃO, 2006). 
Por efeito desses fatos, podem ser levantados três principais fatores que compuseram essa circunstância diferente da ocorrida ao longo da Missão Pimenta Bueno em relação ao caso da Bellegarde. Faz-se necessário, deste modo, elucidar que as teses e as conclusões decorrentes dos debates políticos ocorridos anteriormente não se desfizeram, ou seja, podem ser consideradas como aspectos que influenciaram o processo de tomada de decisão entre o Ministério dos Negócios Estrangeiros, Pedro Alcântara Bellegarde e o governo de Carlos Lopez. A partir desse pressuposto, o primeiro fator a ganhar destaque é a existência de teses mais consolidadas acerca de como a diplomacia deveria atuar frente aos vizinhos platinos, diferentemente do período que compreendeu a Missão Pimenta Bueno, no qual essas ainda estavam em processo de construção, após o momento de saída da longa neutralidade que caracterizara os negócios estrangeiros do Império para com o Prata (VERANO, 2014; CERVO, 1981, p. 49-56). O segundo, influenciado diretamente por esse primeiro fator, pode ser atribuído à pessoa de Paulino José Soares de Souza, o Visconde do Uruguai, cuja figura política frente à chancelaria brasileira trouxe, pela primeira vez, uma grande força que conseguiu formular concepções a serem seguidas pelo seu corpo diplomático, cujos sucessos se transformaram nos alicerces que fundaram tradições a serem seguidas pelo Brasil em sua história. O terceiro refere-se ao ressurgimento da pressão inglesa para o fim do tráfico de escravos, o que demandou grandes esforços do Conselho de Estado e do Parlamento.

\section{Da Neutralidade Relutante para a Atuação Pragmática}

Por decorrência do rompimento da postura de neutralidade do Brasil frente aos problemas existentes na região do Rio da Prata em direção a uma postura proativa quanto à defesa de seus interesses na região, por volta de 1842 (CERVO; BUENO, 2008, p. 109-111), surgiu a necessidade de serem formadas novas estratégias de atuação nesse eixo relacional. A análise da documentação das Atas do Conselho de Estado e dos Anais do Parlamento leva à constatação de uma inicial falta de clareza em como nortear os negócios, principalmente com Buenos Aires. Ao passo que se ampliaram as zonas de pressão, principalmente pelas intenções expansionistas de Rosas e a subsequente demanda paraguaia para a obtenção do reconhecimento de sua independência, formaram-se os primeiros impulsos no Brasil para a saída de um posicionamento de neutralidade e não intervenção rumo a uma política mais incisiva (VERANO, 2014). Embora essa grande rivalidade entre o Brasil e a Argentina possa parecer um fator estático que permeou toda a década de 1840 , 
existiram momentos nos quais a cooperação foi buscada, contudo sem lograr resultados concretos.

Ao longo da vigência da Missão Pimenta Bueno, cujo principal objetivo consolidado foi o reconhecimento da independência do Paraguai (fato que pode ser atribuído à missão, já que nenhum acordo documental ter sido firmado entre ambos os Estados), tornam-se mais claras as disputas que caracterizariam as relações entre Brasil e Argentina até o fim de 1852, com a queda de Rosas na batalha de Monte Caseros (CALÓGERAS, 1998, p. 580-590). Ao passo que o Império objetivava garantir as independências paraguaia e uruguaia, essa última tendo como base o tratado de 1828 e suas implicações legais que dispunham ao Brasil a capacidade de intervenção no caso de haver ameaças à sua independência,, Rosas, por meio do exercício legal do comando da política externa da Confederação, procurava efetivar a tese de que o Paraguai de fato pertenceria ao seu país. Também intervinha auxiliando o partido Blanco no Uruguai, para difundir nesse país os interesses de Buenos Aires. Embora a rivalidade entre Brasil a Argentina possa parecer um fator estático durante a década de 1840, podem ser percebidos momentos nos quais se procurou a cooperação entre ambos, motivados por eventos específicos, como por ocasião da intervenção franco-britânica e da Guerra dos Farrapos, que o governo imperial encontrava grandes dificuldades de findar.

Seguindo essa linha, destacam-se os projetos de tratado que visavam o entendimento mútuo entre o Império e a Confederação de Rosas. A despeito dos protestos por parte de Buenos Aires quanto ao reconhecimento brasileiro da independência paraguaia, assim como das práticas intervencionistas do referido caudilho sobre a navegação fluvial na bacia platina, podem ser destacadas situações nas quais uma concertação entre os dois governos fazia-se necessária. Da parte do Império, destaca-se o tratado de 1843, que tinha como ponto central a cooperação entre ambos os Estados para pôr fim aos distúrbios causados pela Guerra dos Farrapos, o qual foi veementemente criticado na Câmara dos Deputados (Sessão de 21 de agosto de 1845), embora a posteriori de sua ratificação pelo Poder Executivo. Da iniciativa do governo de Rosas, o projeto de tratado de 1846 (Conselho de Estado, sessão de 30 de maio de 1846), com vista à formação de uma aliança para pôr fim à intervenção anglo-francesa no Rio da Prata, reflete o interesse da parte de Buenos Aires por entender-se com o Império, embora esse não tenha logrado frutos (Conselho de Estado, sessão de 28 de setembro de 1846).

Reafirmando o quanto era tido como importante que o governo brasileiro cooperasse nessa questão, a reclamação oficial, datada do mesmo ano, demonstrava 
a insistência nas pressões feitas por Rosas para que o Império, com base o tratado de 1828, interviesse conjuntamente para repelir a atuação estrangeira, entretanto a postura de neutralidade frente à ação franco-britânica tenha sido mantida pelo Brasil (Conselho de Estado, sessão de 28 de setembro de 1846). Conclusivamente, pode ser afirmado que, à época que essas propostas foram postas em pauta, existia uma percepção de que era possível serem estabelecidas relações cooperativas entre ambos, a despeito de essas tentativas de entendimento terem surgido somente em questões específicas. Consequentemente, conforme se observa a inexistência de quaisquer propostas formais de entendimento entre ambas as chancelarias no Parlamento ou no Conselho de Estado após esse período, depreende-se que a percepção que passou a prevalecer nos meios políticos do Império acerca das relações entre Brasil e Argentina era de que os interesses amplamente divergentes de ambos os países dificultavam sobremaneira as tentativas de cooperação.

Ao longo da Missão Pimenta Bueno, puderam ser percebidos os alicerces que constituíram o pensamento político brasileiro sobre como as relações com o governo paraguaio deveriam ser mantidas. As amplas discussões que permearam o Parlamento e o Conselho de Estado acerca de como tratar dos negócios exteriores entre o Brasil e o Paraguai são o principal embasamento para essa afirmação, uma vez que em seu seio uma série de princípios foi construída por meio do debate entre seus membros. O principal temor do Império, de que o recém-instaurado governo de Carlos Lopez se aliasse com Juan Manoel Rosas, foi posto por terra nos primeiros momentos subsequentes à chegada de Pimenta Bueno a Assunção. A condensação entre esses países, a fim de compor um projeto acordado de reconstrução territorial do Vice-Reino do Prata, não mais estava no escopo das preocupações do Império, restando somente a possibilidade de uma anexação forçada oriunda de Buenos Aires (VERANO, 2014).

Sendo essa hipótese descartada e até mesmo ratificada pelas pressões da diplomacia paraguaia para que o Brasil compusesse uma aliança ofensiva, visando derrubar Rosas do governo da Confederação Argentina, surgiu a possibilidade de que uma agenda de negociações pudesse ser conformada entre Assunção e o Rio de Janeiro, de modo a suprimir as pendências decorrentes do pouquíssimo contato entre os dois países até então. Embora tenham sido mantidas as grandes polêmicas nas relações entre Brasil e Paraguai, dentre as quais se têm destaque a definição das fronteiras entre ambos os países, com o consequente aumento das tensões militares no Prata, que eram influenciadas sobremaneira pela presença da Inglaterra e da França, essas pendências diplomáticas perderam o destaque que 
tinham no relacionamento bilateral, ganhando precedência questões mais urgentes e sobre as quais já havia relativa concordância, como a percepção de que Rosas seria a grande ameaça às independências das repúblicas platinas.

Observados esses fatores, pode-se concluir a existência de parâmetros já consolidados nas instituições políticas brasileiras acerca das posições adotadas entre o Brasil e o Paraguai em suas negociações diplomáticas. A percepção de Rosas como um inimigo comum, apesar de o Império optar uma posição de aparente neutralidade, atuando preferivelmente por meio de auxílios aos grupos internos argentinos contrários a esse caudilho, assim como de maneira similar no Uruguai, contribuía fortemente para a formação de um entendimento entre os dois países. Posto que os paraguaios pressionassem o governo brasileiro para que fossem aceitos os limites do tratado colonial de Santo Ildefonso, ao passo que o Império preferia que fosse formada uma comissão de análise para que o uti possidetis de facto fosse implementado nessa definição, esse imbróglio diplomático foi encapsulado, de modo que somente após a queda de Rosas os debates acerca desse tema foram retomados ${ }^{6}$. Por decorrência de uma ameaça externa comum aos dois países, as divergências foram postas de lado, a fim de que os interesses externos comuns fossem bem-sucedidos.

\section{As Concepções de Política Externa do Visconde do Uruguai}

Paulino José Soares de Souza, o Visconde do Uruguai, pode ser considerado um dos mais importantes políticos do Império, principalmente no que concerne à pasta dos Negócios Estrangeiros. Definidor de doutrinas que lograriam frutos para o país, assim como reorganizador do serviço diplomático brasileiro, o referido homem de Estado teve uma duradoura gestão frente à chancelaria, ganhando grande destaque ao ser comparada com as que se estabeleceram ao longo da década de 1840, quase todas de curta duração. Não somente a durabilidade de sua gestão na pasta se destaca, mas também o fato de que, entre sua segunda nomeação, em 8 de outubro de 1849, até sua retirada em setembro de 1853 (TORRES, 2011, p.17), dois gabinetes de partidos diferentes estiveram à frente do sistema parlamentar brasileiro. Esse fato é um dos poucos casos existentes

\footnotetext{
6 As negociações entre Brasil e Paraguai acerca dos limites entre ambos os países somente foi retomada com a Missão Paranhos, já em meados da década de 1850. Conforme seria observado nesse momento posterior, um entendimento entre ambas as diplomacias não se mostrou possível, tendo sido adiadas as negociações, a fim de que um consenso fosse formado, embora essas pendências somente tenham sido sanadas após a Guerra do Paraguai (DORATIOTO, 1989, p. 59).
} 
na história do Brasil, ocorridos apenas com personalidades políticas de grande expressão ${ }^{7}$ cujos mandatos passaram ao largo de disputas partidárias: a pessoa de Paulino José Soares de Souza certamente pode ser incluída em tal panteão, como um dos grandes nomes da política exterior do Brasil.

Embora de curta duração, sua primeira gestão na pasta dos Estrangeiros ocorreu ao longo do ano de 1844, sendo já possível identificar os principais aspectos que caracterizariam sua forma de comando. Uma aproximação pragmática para com o "hemisfério americano" destaca-se, cuja origem pode ser atribuída não somente aos ideais que fundamentaram esse pleito ainda na década de 1830 a maior simetria nas relações -, mas também a quantidade de pendências que dificultavam as relações entre o Império e seus vizinhos, como a definição de fronteiras e as políticas de poder implementadas por Rosas na região (FERREIRA, 2013). Em decorrência do pouco tempo à frente desse Ministério, assim como das alternâncias de poder internas do país, não foi possível que suas teses fossem aplicadas continuamente, fato que contribui para a caracterização do período que vai até o seu retorno à Chancelaria como de "neutralidade relutante"8 (VERANO, 2014).

Em decorrência da maior estabilidade político-institucional proporcionada pela criação do cargo de Presidente do Conselho de Ministros (1847), o qual trouxe consigo uma melhor definição nos gabinetes políticos que compunham a base governativa do Império, foi possível também uma maior estabilidade dos líderes das respectivas pastas ministeriais (BARBOSA, 2007). Dessa forma, enquanto perdurasse a legislatura, a definição dos Ministros era feita pelo Presidente do Conselho, de modo que uma maior continuidade dos nomes que compunham cada Ministério tornava-se mais provável. O grande período durante o qual o futuro Visconde do Uruguai comandou a Chancelaria Imperial, em decorrência disso, pode ser compreendido não somente por sua capacidade governativa e sucesso em empreender uma política externa frutuosa, mas também em virtude de um quadro político com maior estabilidade, favorável à implementação de políticas de mais longo prazo, não sendo interrompidas por súbitas trocas de governo (FERREIRA, 2013).

7 Dentre esses homens de Estado, o que teve sua trajetória mais marcante de atemporalidade frente ao Ministério das Relações Exteriores foi o Barão do Rio Branco (1902-1912), cujo profissionalismo e sucesso em suas empreitadas tornaram-no uma referência para as futuras gerações da diplomacia brasileira.

8 O conceito de Neutralidade Relutante visa explicar o processo de formação de pensamento político contido nas instituições políticas do Império à luz do status formalmente neutral com que as relações com os países do Prata eram tratadas (VERANO, 2014). 
Um dos principais motivos que notabilizou sua passagem pelo Ministério foi a definição de uma doutrina para a negociação das fronteiras brasileiras. A despeito da existente tradição advinda de Alexandre de Gusmão e do seu uso nas negociações do Tratado de Madri (1750), o uti possidetis de facto ${ }^{9}$, ou seja, o direito de propriedade do território para a nação que de fato o ocupar, não era um princípio consensual dentro dos quadros políticos do Império, muito em virtude da influência exercida pelos limites estabelecidos pelos tratados coloniais. A despeito de o desenho fronteiriço entre as colônias hispano-americanas e a lusitana ter sido definido com aquele tratado, as instabilidades e disputas entre ambos os colonizadores fizeram com que outros acordos lindeiros fossem estabelecidos, como o Tratado de Santo Ildefonso (1777) e o de Badajóz (1801) (GOES, 1991, p. 114-118). Desse fato, infere-se que, embora existisse um parâmetro de onde as colônias começavam e terminavam na América do Sul, esse assunto não era ponto pacífico, mas, sim, motivo de origem de grandes controvérsias, com destaque para os casos dos territórios coloniais na região do Prata, devido à sua importância estratégica. Por fim, deve-se destacar que a grande faixa lindeira do Brasil, embora estivesse relativamente bem traçada, não contava com delimitações precisas, devido à ausência de comissões demarcadoras em diversas partes do território e às diferentes nomenclaturas adotadas por nativos e por exploradores para os rios e acidentes geográficos que serviam como parâmetros delimitadores.

\section{Novas Reflexões sobre Velhos Assuntos: a Pressão Internacional contra o Tráfico de Escravos}

Ao longo da parte final da década de 1840, um novo tema de grande importância surgiu na política externa brasileira. Embora não seja, de fato, inovador, pois seus debates remontam a tempos anteriores à própria independência política do Brasil, pode-se dizer que há um recrudescimento dessa questão, tomando frente nos debates políticos das instituições. A pressão internacional contra o tráfico de escravos acaba por ressurgir em virtude da publicação da Bill Arbedeen na Inglaterra, em 1848 (BETHELL, 2002). Mesmo que, desde 1831, o tráfico de escravos estivesse proibido no Império pela Lei Feijón ${ }^{10}$, sua prática ainda era

9 Deve-se observar que o primeiro chanceler brasileiro que fez ampla defesa do uso do uti possidetis de facto, no Império, foi Duarte da Ponte Ribeiro, contudo, os sucessos decorrentes dessa doutrina de limites vieram mais veementemente na gestão do Visconde do Uruguai (CERVO; BUENO, 2008, p. 92-93).

10 A Lei Feijó, embora tenha sido o primeiro instrumento legal brasileiro a tentar extinguir o tráfico de escravos, 
realidade, tendo a permissão de ataque à navios suspeitos de tráfico concedida às embarcações britânicas pela Bill causado relevantes repercussões no Brasil, uma vez que colocava em risco os lucros advindos do infame comércio.

Para a compreensão desta mudança de foco nas instituições, é importante ter noção das limitações existentes na própria estrutura político-administrativa destas no Império. Diferentemente do que há hodiernamente, em que existe um complexo aparato estatal de apoio aos políticos e às pastas ministeriais, no período analisado esses alicerces são bastante precários. Referencial importante é o próprio número diminuto de sessões parlamentares que ocorriam ao longo do ano, como, por exemplo, no ano de 1845, quando somente durante cinco meses houve sessões plenárias do Senado. O Conselho de Estado, por sua vez, tinha seu funcionamento restrito pela própria inexistência de uma estrutura física específica para suas reuniões, as quais ocorriam em salas do Paço de São Cristóvão. A estrutura disponível e o próprio rito de trabalho eram, desse modo, limitadores da pluralidade dos temas debatidos, sendo mais comumente tratados um a um, conforme exigiam um entendimento proveniente desses estadistas, embora isso não desfizesse a importância de suas ideias para a prática política.

O tráfico negreiro, além de ter forte vínculo com uma tradição social presente desde o período colonial, que relacionava poder e riqueza à posse de cativos para o exercício laboral (SILVA, 2011, p. 43), recaía sobre o cerne da economia do país, macroestruturado basicamente na exportação de bens primários cuja produção se encontrava alicerçada no escravagismo. Pela mesma lógica, a atividade negreira sustentava uma porção importante da elite brasileira, que tinha grande poder de pressão sobre os políticos do Império, quando não eram eles próprios membros do governo. Em uma direta vinculação, o desenvolvimento do setor agroexportador do país esteve diretamente relacionado às diversas dinâmicas do escravagismo, que incluíam desde a captura, na África, o traslado ultramarino, até sua comercialização no Brasil. De modo tácito, é possível afirmar que ações que viessem a desamarrar todo esse ordenamento eram vistas com temor pelas elites do Império, por colocar em risco a estrutura sobre as quais elas estavam apoiadas.

As sessões do Conselho de Estado que versaram sobre o tráfico, ao longo da Missão Bellegarde, tiveram substantiva preeminência sobre todas as outras

foi somente com a promulgação da Lei Euzébio de Queiróz, em 1850, após a entrada em vigor da britânica Bill Arbedeen, em 1848, que o tráfico de escravos foi extinto de jure no Brasil 
debatidas dentro desta instituição ${ }^{11}$. O pragmatismo e intervencionismo que passou a existir na ação britânica sobre os navios negreiros, diferentemente das pressões políticas que anteriormente eram seu instrumento preferencial, passaram a impactar a economia brasileira progressivamente. Concomitantemente, observamse significativas repercussões políticas que tomaram conta de boa parte da agenda não só do Conselho como do Parlamento, deixando outras pautas de política internacional em estado latente.

À luz da função primordial dos órgãos da burocracia do Império aqui analisados para a política externa (formação de ideias e concepções), em paralelo ao que anteriormente fora dito sobre as suas limitações operacionais, procurase dar entendimento sobre como o tema do combate internacional ao tráfico de escravos reduziu a atenção do Parlamento e do Conselho de Estado para o Prata. A despeito de as relações entre o Império do Brasil e esses vizinhos estarem cada vez mais tensas e a possibilidade de guerra mais evidente, já havia uma série de preceitos anteriormente desenvolvidos com os quais tanto o Ministério como Bellegarde podiam contar para basilar suas ações.

\section{Resultados da Missão}

O grande legado da Missão Bellegarde ao Paraguai, em termos gerais, pode ser atribuído ao fato de ter sido assinado, em 25 de dezembro de 1850, o Tratado de Aliança Defensiva entre o Império do Brasil e a República do Paraguai. As modificações sistêmicas decorrentes do recrudescimento das relações regionais no Prata, em virtude da maior iminência de um conflito militar entre o Brasil e a Confederação de Rosas, tornaram possível que esse tipo de acordo, que outrora fora veementemente criticado, fosse aprovado. Embora esse caso constitua uma passagem recorrentemente retratada pela historiografia brasileira (CERVO; BUENO, 2008; CALÓGERAS, 1998; RODRIGUES; RODRIGUES 1995; HOLANDA, 1965), o que se destaca aqui é o fato de não ter havido nenhuma repercussão, tanto no Parlamento quanto no Conselho de Estado, acerca da assinatura desse acordo internacional. Comparativamente à Missão Pimenta Bueno, assim como no episódio do envio do representante diplomático paraguaio ao Brasil, em cujos casos as pretensões de Carlos Lopez de formar uma aliança contra Rosas foram

11 Dentre os temas debatidos na Seção dos Negócios Estrangeiros do Conselho de Estado, entre os anos de 1849 e 1853, dentre os quarenta e seis pareceres firmados, dezenove têm em seu título o tema "tráfico de escravos", afora os que versavam sobre os negócios entre Brasil e Grã-Bretanha que continham aspectos desse mesmo tema. 
veementemente criticadas nos meios políticos do Império, o tratado negociado por Bellegarde teve consequência diametralmente oposta.

No caso da Câmara, conforme pode ser analisado na sessão do dia 10 de janeiro de 1852, há a distribuição do texto do tratado aos parlamentares, embora nenhum comentário tenha sido feito acerca do conteúdo do mesmo. Este fato pode ser atribuído ao tempo que se passou entre a assinatura do supracitado tratado bilateral e sua chegada ao Parlamento, quando já havia, praticamente, uma definição de como o conflito militar entre o Império e seus aliados contra Rosas seria definido, pela progressiva perda de apoio interno que o caudilho buenairense sofria, o que contribuiu para corroer suas forças militares. No âmbito do Conselho de Estado, por ser uma casa revisora e de aconselhamento direto do Imperador, com a existente definição das diretrizes de como o relacionamento com o Paraguai deveria ser lidado no caso de alianças, não houve necessidade de serem feitos novos debates, pois as teses já se encontravam definidas e a forma como o Tratado de Aliança se compôs respeitava os preceitos anteriormente debatidos no Conselho.

A Missão Bellegarde ao Paraguai tem características que a destaca no que concerne aos temas e acordos firmados, assim como aos seus impactos nas instituições políticas do Império. Por efeito do fortalecimento das rusgas entre o Império e Buenos Aires, decorrentes da posição desse governo de reconstruir territorialmente o Vice-Reino do Prata, do impedimento à navegação fluvial nessa bacia, assim como do apoio a grupos contrários aos interesses brasileiros no Uruguai, a aproximação política entre Brasil e Paraguai tornou-se mais favorável. A despeito dos temas que se tornariam pendências diplomáticas entre os dois países, como a definição dos limites territoriais e a forma como a navegação nos rios internacionais compartilhados por ambos seria feita, o fato de existir uma potência percebida como rival pelos dois países proporcionou que essas referidas agendas de negociação fossem deixadas em espera, a fim de que interesses mais imediatos fossem atendidos.

Embora não se possa afirmar que Brasil e Paraguai tornaram-se aliados históricos, pois o acordo de Aliança Defensiva somente circunscreveu a necessidade que ambos tinham de combater as ações interventivas de Rosas, pode-se entender que houve relativo sucesso do empreendimento diplomático liderado por Bellegarde. Em decorrência das boas relações mantidas com o vizinho guarani, foi possível ao Império fortalecer o pleito da independência do Paraguai, assim como aproximar esse país para sua órbita de aliados, numa atitude de preparo, caso a rivalidade 
entre o Império e Buenos Aires se acirrasse. Mas já que, em termos práticos, as forças paraguaias não tiveram atuação direta nos combates contra as tropas de Rosas (e a aliança, logo após a queda do governador de Buenos Aires em Monte Caseros, se findou, devolvendo as praças diplomáticas aos temas ainda pendentes do relacionamento entre Brasil e Paraguai), pode ser afirmado que a aliança entre os dois países não se tornou necessária em seu escopo prático, ou seja, militar. Conforme se depreende dos momentos posteriores aos analisados no presente trabalho, com o fim da inimizade comum aos dois países, a proximidade que se formou ao longo da década de 1840 deu lugar a um sistema de progressivas tensões, as quais culminariam com o confronto bélico que marcou a década de 1860, a Guerra do Paraguai.

\section{Conclusões}

A análise das documentações históricas relativas à Missão Bellegarde revelou aspectos para a compreensão da política externa brasileira para o Prata. Tendo como ponto de partida as heranças da missão predecessora, que partiu de um diálogo mais restrito ao âmbito do Ministério dos Negócios Estrangeiros, desprendendo-se em direção às instituições, tinha-se como resultado esperado para a Bellegarde um cenário similar. Percebeu-se, desde as instruções do Marquês de Olinda, uma preocupação crescente nas relações com a Argentina, de modo que essa ação diplomática fora tratada com bastante cautela, porém com muita importância para as relações sub-regionais. De um cenário em que relativa concertação ainda era possível, dirigiu-se para uma progressiva heterogeneidade de posições entre o Rio de Janeiro e Buenos Aires, de modo a dissociar cada vez mais as forças que viriam a entrar em conflito.

Tendo como embasamento os quase inexistentes pronunciamentos das instituições que o presente artigo analisou, o Parlamento e o Conselho de Estado, procurou-se dar resposta para essa forma de inação observada em ambos. Elementos diferentes, porém, complementares, foram importantes para esse esforço compreensivo: dentre eles, as já existentes concepções de como se relacionar com o Paraguai no subsistema platino; a chancelaria do Visconde do Uruguai; e o surgimento de um novo tema que demandou grande atenção das instituições: o combate inglês ao tráfico negreiro. A conglomeração desses é a resposta que se dá a pergunta de pesquisa que movimentou este trabalho, que teve, no 
episódio histórico destacado, a assinatura de uma aliança entre o Império e o Paraguai a partir da percepção de que o governo de Rosas, em Buenos Aires, era um inimigo comum.

A comparação entre os mandatos de Bellegarde e de Pimenta Bueno demonstra uma constante nas agendas do relacionamento brasileiro-guarani, sobre os quais poucos avanços foram conseguidos por ambos os empreendimentos políticos. O acirramento das tensões platinas, contudo, serviu como elemento de coesão sobre um aspecto que, por fins da década de 1840, era praticamente ponto pacífico: a necessidade de conter o expansionismo de Rosas, perigoso para os interesses de ambos os países. A relutância que outrora caracterizavas as posturas brasileiras para promover uma saída de sua condição formalmente neutral mostrou-se cada vez mais insustentável, percebida pela assinatura do Tratado de 1850 .

Os esforços diplomáticos da década de 1840 podem ser entendidos como centrais na construção das dinâmicas de poder que culminaram na Guerra contra Rosas e que puseram por terra seu governo em Buenos Aires, em 1852. Mesmo sem atuações diretas das instituições ao longo do seu mandato, que seria findado já em 1853, é possível, sim, entender as concepções que nortearam os caminhos traçados nas negociações de Bellegarde em Assunção como influenciadas, mesmo que parcialmente, pelo Parlamento e pelo Conselho. Nesse sentido, procura-se por fim ressaltar a importância da análise sobre essa Missão, uma vez que ela é um componente central nos caminhos traçados pela política externa brasileira do Império para seu principal eixo de atuação, o subsistema do Prata.

\section{Referências Bibliográficas}

BARBOSA, Silvana Mota. O Conselho de Ministros no Império do Brasil. Locus: Revista de História. v. 13, $\mathrm{n}^{\circ}$ 1, p. 52-62. 2007.

BETHELL, Leslie. Abolição do comércio brasileiro de escravos: A Grã-Bretanha, o Brasil e a questão do comércio de escravos: 1807-1869. Brasília: Senado Federal. 2002.

BRASIL, Câmara dos Deputados. Anais da Câmara dos Deputados (1840-1853). Brasília, 1978.

BRASIL, Ministério das Relações Exteriores. Conselho de Estado (1842-1889): consulta da Seção dos Negócios Estrangeiros. Brasília: 1978.

BRASIL, Senado Federal. Anais do Senado do Império (1840-1853). Brasília, 1978.

CALÓGERAS, João Pandiá. A Política Exterior do Império. Volume 3. Brasília: Editora Senado Federal. 1998. 
CARVALHO, José Murilo de. Teatro de Sombras: a política imperial. São Paulo: Vértice; Rio de Janeiro: IUPERJ. 1988.

CERVO, Amado. O Parlamento Brasileiro e as Relações Exteriores (1826-1889). Brasília: UnB. 1981.

CERVO, Amado. BUENO, Clodoaldo. História da Política Exterior do Brasil. Brasília: Editora UnB. 2008.

DORATIOTO, Francisco. As Relações entre o Império do Brasil e a República do Paraguai(1822-1889). Brasília, 2 v. Tese - UnB/his. 1989.

FERREIRA, Gabriela Nunes. Paulino José Soares de Souza (Visconde do Uruguai): a construção dos instrumentos da diplomacia brasileira. In: PIMENTEL, José Vicente de Sá (org.). Pensamento Diplomático Brasileiro: formuladores e agentes da política externa (1750-1950). Brasília: FUNAG. 2013.

FLORIA, Carlos. BELSUNCE, César. Historia de lós Argentinos. Buenos Aires: Larousse. 2004. GOES, Synésio Sampaio. Navegantes, Bandeirantes, Diplomatas: Aspectos da descoberta do continente, da penetração do território brasileiro extra-Tordesilhas e do estabelecimento das fronteiras da Amazônia. Brasília: IPRI. 1991.

HOLANDA, Sérgio Buarque. História Geral da Civilização Brasileira. Tomo II: O Brasil Monárquico. São Paulo: Difusão Europeia do Livro. 1965.

MANCHESTER, Alan Krebs. Preeminência inglesa no Brasil. São Paulo: Brasiliense, 1973. MORGENTHAU, Hans. A Política entre as Nações. Brasília: Editora Universidade de Brasília, 2003.

RODRIGUES, José Honório; RODRIGUES, Leda Boechat (Coord.) Uma história diplomática do Brasil: (1531-1945). Rio de Janeiro: Civilização Brasileira. 1995.

SILVA, Alberto da Costa. População e Sociedade. In: SCHWARCZ, Lilia Moritz (dir). História do Brasil Nação: 1808 - 2010. Volume 1: Crise Colonial e Independência. Rio de Janeiro: Editora Objetiva. 2011.

SOARES, Teixeira. História da Formação das Fronteiras do Brasil. Rio de Janeiro: Biblioteca do Exército, 1973.

SOUZA, José Antônio Soares. A Missão Bellegarde ao Paraguai (1849-1852): Documentos. Brasília: Ministério das Relações Exteriores, v. 2 e 3. 1970.

TORRES, Miguel Gustavo. O Visconde do Uruguai e sua atuação diplomática para a consolidação da política externa do Império. Brasília: Fundação Alexandre de Gusmão. 2011. VALLE, Diana Jorge. A Influência do Conselho de Estado nas relações entre o Império brasileiro e os países do Rio da Prata (dissertação). Ministério das Relações Exteriores: Instituto Rio Branco. 2011.

VERANO, Pedro Henrique. O Conselho de Estado e a Missão Pimenta Bueno ao Paraguai: formação de tendências de política externa no Brasil Império. Meridiano 47 (UnB), v. 15, p. 3-10, 2014. Disponível em: http://periodicos.unb.br/index.php/MED/article/ view/10266. Acesso em 20 dez. 2016. 